\title{
Front Matter: Volume 9810
}

, "Front Matter: Volume 9810," Proc. SPIE 9810, International Conference on Atomic and Molecular Pulsed Lasers XII, 981001 (13 January 2016); doi: $10.1117 / 12.2230865$

SPIE Event: XII International Conference on Atomic and Molecular Pulsed Lasers, SPIE. 2015, Tomsk, Russian Federation 


\title{
PROCEEDINGS OF SPIE
}

\section{International Conference on Atomic and Molecular Pulsed Lasers XII}

\author{
Victor F. Tarasenko \\ Andrey M. Kabanov \\ Editors
}

\section{3-18 September 2015 \\ Tomsk, Russian Federation}

Sponsored by

Russian Foundation for Basic Research (Russian Federation)

Siberian Branch of Russian Academy of Sciences (Russian Federation)

TOPAZ Research and Inculcation Enterprise (Russian Federation)

Crystaltechno Ltd. (Russian Federation)

SP Equipment (Russian Federation)

Intech Analytics Corporation (Russian Federation)

IC Specpostavka (Russian Federation)

CLZ Ltd. (Russian Federation)

Published by

SPIE 
The papers in this volume were part of the technical conference cited on the cover and title page. Papers were selected and subject to review by the editors and conference program committee. Some conference presentations may not be available for publication. Additional papers and presentation recordings may be available online in the SPIE Digital Library at SPIEDigitallibrary.org.

The papers reflect the work and thoughts of the authors and are published herein as submitted. The publisher is not responsible for the validity of the information or for any outcomes resulting from reliance thereon.

Please use the following format to cite material from these proceedings:

Author(s), "Title of Paper," in International Conference on Atomic and Molecular Pulsed Lasers XII, edited by Victor F. Tarasenko, Andrey M. Kabanov, Proceedings of SPIE Vol. 9810 (SPIE, Bellingham, WA, 2015) Six-digit Article CID Number.

ISSN: 0277-786X

ISSN: 1996-756X (electronic)

ISBN: 9781510600515

Published by

SPIE

P.O. Box 10, Bellingham, Washington 98227-0010 USA

Telephone +1 3606763290 (Pacific Time) · Fax +1 3606471445

SPIE.org

Copyright @ 2015 , Society of Photo-Optical Instrumentation Engineers.

Copying of material in this book for internal or personal use, or for the internal or personal use of specific clients, beyond the fair use provisions granted by the U.S. Copyright Law is authorized by SPIE subject to payment of copying fees. The Transactional Reporting Service base fee for this volume is $\$ 18.00$ per article (or portion thereof), which should be paid directly to the Copyright Clearance Center (CCC), 222 Rosewood Drive, Danvers, MA 01923. Payment may also be made electronically through CCC Online at copyright.com. Other copying for republication, resale, advertising or promotion, or any form of systematic or multiple reproduction of any material in this book is prohibited except with permission in writing from the publisher. The CCC fee code is 0277-786X/15/\$18.00.

Printed in the United States of America.

Publication of record for individual papers is online in the SPIE Digital Library.

\section{SPIE. DIGITAL}

Paper Numbering: Proceedings of SPIE follow an e-First publication model. A unique citation identifier (CID) number is assigned to each article at the time of publication. Utilization of CIDs allows articles to be fully citable as soon as they are published online, and connects the same identifier to all online and print versions of the publication. SPIE uses a six-digit CID article numbering system structured as follows:

- The first four digits correspond to the SPIE volume number.

- The last two digits indicate publication order within the volume using a Base 36 numbering system employing both numerals and letters. These two-number sets start with 00, 01, 02, 03, 04, $05,06,07,08,09,0 A, 0 B \ldots$. OZ, followed by 10-1Z, 20-2Z, etc. The CID Number appears on each page of the manuscript. 


\title{
Contents
}

\author{
ix Authors \\ xi Conference Committee \\ $\mathrm{xv}$ Introduction
}

SESSION A GAS AND PLASMA LASERS, METAL VAPOR

$981002 \quad$ KrF laser with a power of 100 W [9810-12]

981003 Anomalies of the $\mathrm{XeCl}$ : laser output beam formation [9810-23]

981004 Laser action in runaway electron pre-ionized diffuse discharges [9810-101]

981005 Self-sustained volume discharge in $\mathbf{C}-\mathrm{C}_{4} \mathrm{~F}_{8}$ [9810-31]

981006 Comparison of CuBr-laser frequency operation modes [9810-32]

981007 Spatial and electron structure of substituted gold clusters [9810-47]

981008 Formation of laser irradiation by non-uniform pumping discharge of KrF laser [9810-53]

981009 Metal vapor lasers with increased reliability [9810-57]

$98100 \mathrm{~A}$ Influence of inversion creation processes in atomic transitions on four-wave parametric oscillation process (FWPOP) under optical pumping of barium and europium vapor [9810-62]

\section{SESSION B PHOTONICS OF OPTICAL MATERIALS, OPTOELECTRONICS}

$9810 \mathrm{OB} \quad$ Intramolecular photo-physical processes and spectral-luminescence properties of a dye merocyanine 540 and its complexes with water [9810-4]

$98100 \mathrm{C}$ The influence of thermolysis time on the absorption spectra of polyvinyl chloride in acetophenone [9810-30]

9810 OD Simple approach to detection and estimation of photoactivity of silver particles on graphene oxide in aqueous-organic dispersion [9810-40]

9810 OE The interaction between humic acid and naphthalene after exposure to visible and UV light [9810-68]

9810 OF Quantum-chemical study of electronically excited states of protolytic forms of vanillic acid [9810-69] 
$98100 \mathrm{G} \quad$ Multiple filamentation of laser beams with different diameters in the air at a 150-meter path [9810-1]

$9810 \mathrm{OH} \quad$ Filamentation of collimated Ti:sapphire-laser pulses in the glass [9810-2]

98100 Filamentation of collimated Ti:sapphire-laser pulses in water [9810-201]

$98100 \mathrm{~J}$ Optimization of the laser beam propagation conditions in the prism stretcher of THL-100 multiterawatt laser system [9810-21]

9810 OK Some results of the propagation of the high-power terawatt femtosecond laser radiation in different media [9810-22]

$9810 \mathrm{OL} \quad$ Study of the population inversion mechanisms and superradiance on ion transitions of molecular nitrogen in the filament [9810-73]

$98100 \mathrm{M} \quad$ Features of infrared ultrabroadband supercontinuum generation under filamentation of femtosecond laser pulses in solid media with various bandgaps [9810-38]

$9810 \mathrm{ON}$ The accumulation of femtosecond laser radiation energy in crystals of lithium fluoride [9810-52]

981000 Evolution of spatial and energy characteristics conically divergent beams in the XeF(C-A) amplifier [9810-54]

9810 OP The study of second harmonic generation of the femtosecond laser pulses with a 950nm central wavelength [9810-55]

$98100 Q \quad$ Macroscopic model of formation of the domain of multiple filamentation in glass and water [9810-56]

\section{SESSION D LASER SYSTEMS AND NEW LASER AND OPTICAL TECHNOLOGIES, LASER APPLICATIONS}

9810 OR Optical spectra and radiative recombination of electron-hole liquid in diamonds [9810-3]

9810 OS Influence of complex impact of the picosecond electron beam and volume discharge in atmospheric-pressure air on the electronic properties of MCT epitaxial films surface [9810-5]

9810 0T Features of the synthesis of nanocolloid oxides by laser ablation of bulk metal targets in solutions [9810-6]

$98100 \mathrm{U}$ Influence of pulsed nanosecond volume discharge in atmospheric-pressure air on the electrical characteristics of MCT epitaxial films [9810-10] 
9810 OV Surface modification of aluminum by runaway electron preionized diffuse discharges in different gases at atmospheric pressure [9810-11]

9810 OW Room temperature Fe $\mathrm{Fe}^{2+}: \mathrm{ZnS}$ laser [9810-16]

9810 0X Modification of various metals by volume discharge in air atmosphere [9810-18]

9810 OY Modification of the surface layers of copper by a diffuse discharge in atmospheric pressure air [9810-20]

$98100 Z$ The inactivation of eggs of helminthes under the action of narrowband ultraviolet radiation of excilamps [9810-76]

981010 Laser-Induced Breakdown Spectroscopy (LIBS): specific applications (Plenary Paper) [9810-74]

981011 Optical parametric oscillators in lidar sounding of trace atmospheric gases in the mid infrared region [9810-72]

981012 Modification and ab-initio spectroscopic application of modified commerce terahertz spectrometer by using homemade parts [9810-27]

981013 Synthesis and characterization of chitosan-based polyelectrolyte complexes, doped by quantum dots [9810-34]

981014 Modification of water in a nanosecond diffuse discharge with fast electron preionization at a short voltage rise time [9810-37]

981015 Using laser technological unit ALTI "Karavella" for precision components of IEP production [9810-41]

981016 Possibilities of using pulsed lasers and copper-vapour laser system (CVL and CVLS) in modern technological equipment [9810-42]

981017 Linear and NLO spectroscopy of GaSe and InSe nanoparticles formed via laser ablation [9810-43]

981018 LIDAR for remote sensing of contaminations on water and earth surfaces taking place during oil-gas production [9810-44]

981019 Structure of salts solution in polar dielectric liquids and electrically induced separation of solvated ions [9810-45]

$98101 \mathrm{~A}$ An effective way to address global environmental and energy problems [9810-46]

$98101 \mathrm{~B}$ Acoustoplasma synthesis of nanoparticles of metal oxides and formation of nanostructured coatings on material surfaces under ultrasonic treatment [9810-48]

9810 1C Physical and chemical properties of tungsten oxide nanoparticles obtained in plasma discharge under ultrasonic action [9810-49] 
9810 ID Physical and chemical processes of low-temperature plasma decomposition of liquids under ultrasonic treatment [9810-50]

9810 1E Measurement of reflection coefficients of organic and non-organic media and materials in UV spectrum [9810-61]

$98101 \mathrm{~F}$ From a metal vapor laser projection microscope to a laser monitor (by the 50 -year anniversary of metal vapor lasers) [9810-64]

$98101 G$ The laser-induced electron-hole liquid in the diamond: critical lattice temperature and non-equilibrium carrier density [9810-65]

9810 1H Metrology for terahertz time-domain spectrometers (Plenary Paper) [9810-67]

\section{SESSION E NON-COHERENT UV AND VUV-RADIATION SOURCES}

981011 A new DBD-driven atmospheric pressure plasma jet source on air or nitrogen [9810-19]

$98101 \mathrm{~J} \mathrm{Power} \mathrm{distribution} \mathrm{between} \mathrm{electrons} \mathrm{and} \mathrm{ions} \mathrm{in} \mathrm{the} \mathrm{dielectric} \mathrm{barrier} \mathrm{discharge} \mathrm{in} \mathrm{Xe}-\mathrm{Cl}_{2}$ mixtures and radiation of $\mathrm{Xe}_{2}{ }^{*}$ and $\mathrm{XeCl}^{*}$ excimer molecules [9810-75]

9810 1K Application of excilamps in agriculture and animal breeding (review) [9810-24]

$98101 \mathrm{~L}$ Thermal equilibrium in gas-discharge plasma of low pressure mercury lamp [9810-35]

$98101 \mathrm{M}$ Parameters of REP DD's plasma formed during the pulse and pulse-periodic modes in dense gases [9810-36]

$98101 \mathrm{~N}$ The Townsend coefficient of ionization in atmospheric pressure rare gas plasma [9810-51]

SESSION F CONVERSION OF LASER RADIATION, OPTOELECTRONIC DEVICES

981010 Physical origins of double peak phase matching in GaSe [9810-8]

9810 IP Optical rectification and down-conversion of fs pulses into mid-IR and THz range in $\mathrm{GaSe}_{1-\mathrm{x}} \mathrm{S}_{\mathrm{x}}[9810-9]$

$98101 Q \quad$ The interaction of broadband laser irradiation with plasma of electric discharges near narrow resonances [9810-14]

9810 IR Characteristics of a polycrystalline $\mathrm{ZnSe}: \mathrm{Fe}^{2+}$ laser at room temperature [9810-15]

9810 is The modeling of supercontinuum generation in photonic-crystal fibre in the spectral broadening unit of high-intensity laser system [9810-71]

$98101 \mathrm{~T}$ Model studies of THz-range generation by down-conversion in GaSe and GaSeS crystals [9810-25] 
$98101 \mathrm{U}$ Dielectric barrier discharge $\mathrm{KrCl}$ - and $\mathrm{XeCl}$-excilamps radiation power control by pressure jump method [9810-26]

$9810 \mathrm{lV}$ Influence of thermal deformation processes on phase-matching temperature bandwidth in different nonlinear frequency conversion crystals [9810-70]

\section{SESSION G BIOPHOTONICS}

9810 IW Investigation of the effect of VUV radiation on the viability of microfungi spores [9810-17]

$98101 \mathrm{X}$ Laser detection of $\mathrm{CO}_{2}$ concentration in human breath at various diseases [9810-33]

9810 1Y Applications of principal component analysis to breath air absorption spectra profiles classification [9810-58]

981012 Determination of component concentrations in models of exhaled air samples using principal component analysis and canonical correlation analysis [9810-59]

981020 Thermal interaction of biological tissue with nanoparticles heated by laser radiation [9810-63]

981021 The reveal of a set of informative features in the task of diagnosis on a base of exhaled air absorption spectra analysis using nonparametric algorithms of pattern recognition [9810-66] 
Proc. of SPIE Vol. $9810981001-8$

Downloaded From: https://www.spiedigitallibrary.org/conference-proceedings-of-spie on 25 Apr 2023 Terms of Use: https://www.spiedigitallibrary.org/terms-of-use 


\title{
Authors
}

Numbers in the index correspond to the last two digits of the six-digit citation identifier (CID) article numbering system used in Proceedings of SPIE. The first four digits reflect the volume number. Base 36 numbering is employed for the last two digits and indicates the order of articles within the volume. Numbers start with 00, 01, 02, 03, 04, 05, 06, 07, 08, 09, OA, OB...0Z, followed by 10-1Z, 20-2Z, etc.

\author{
Abuzova, N. V., 13 \\ Ageev, Boris G., $1 \mathrm{X}$ \\ Alekseev, S. V., OJ, ON, OP \\ Allahverdiyev, K., 17, 18 \\ Andreev, M. V., 02 \\ Andreev, Yu. M., 12, 10, 1P, 1T \\ Andrienko, O., $1 \mathrm{~A}$ \\ Apeksimov, D. V., OG, $\mathrm{OH}, \mathrm{Ol}, \mathrm{OQ}$ \\ Apresyan, L. A., OC, OD \\ Arapov, Yury D., IV \\ Ashurbekov, N. A., 1Q \\ Avdeev, Sergey M., OZ \\ Avtaeva, S. V., $1 \mathrm{~J}$ \\ Baasankhuu, N., ON \\ Babushkin, P. A., OK \\ Bazyl', O. K., OB \\ Belevtsev, A. A., 05 \\ Belov, V. V., IE \\ Benken, K., IW \\ Betina, L. L., 15 \\ Bezrodnyy, Dmitriy A., OS \\ Borisov, A. V., 1Y, 1Z, 21 \\ Bukhtsooj, O., ON \\ Bukin, O. A., $\mathrm{OH}, \mathrm{OI}$ \\ Bulychev, N. A., 07, 15, 16, 1B, 1C, 1D \\ Bulygin, A. D., OQ \\ Burnashov, A. V., OK \\ Bychkov, Yurii I., 08 \\ Chadraa, B., ON \\ Chen, C. H., 07, 15 \\ Chernov, A. A., 1B \\ Chudinova, Yulia V., IK \\ Chursin, A. D., 15 \\ Ciganovic, J., 10 \\ Didenko, Maria $V_{\text {., }} 1 \mathrm{U}$ \\ Dresvyanskiy, V.P., ON \\ Dvoretskii, Sergei A., OS, OU \\ Dyakov, Yu. A., 07, 15 \\ Dzyadukh, Stanislav M., OU \\ Erofeev, Mikhail V., OV, OX, OY \\ Evtushenko, G. S., IF \\ Fedorov, A. I., 03, 06 \\ Feofanov, I. N., OC, OD, 15, 16 \\ Firsov, K. N., 05, OW, $1 R$ \\ Frolov, S. A., OM \\ Galkina, S., IW \\ Garelina, S., IA \\ Gavrishchuk, E. M., OW, IR \\ Genin, Dmitrii E., OR, 1G
}

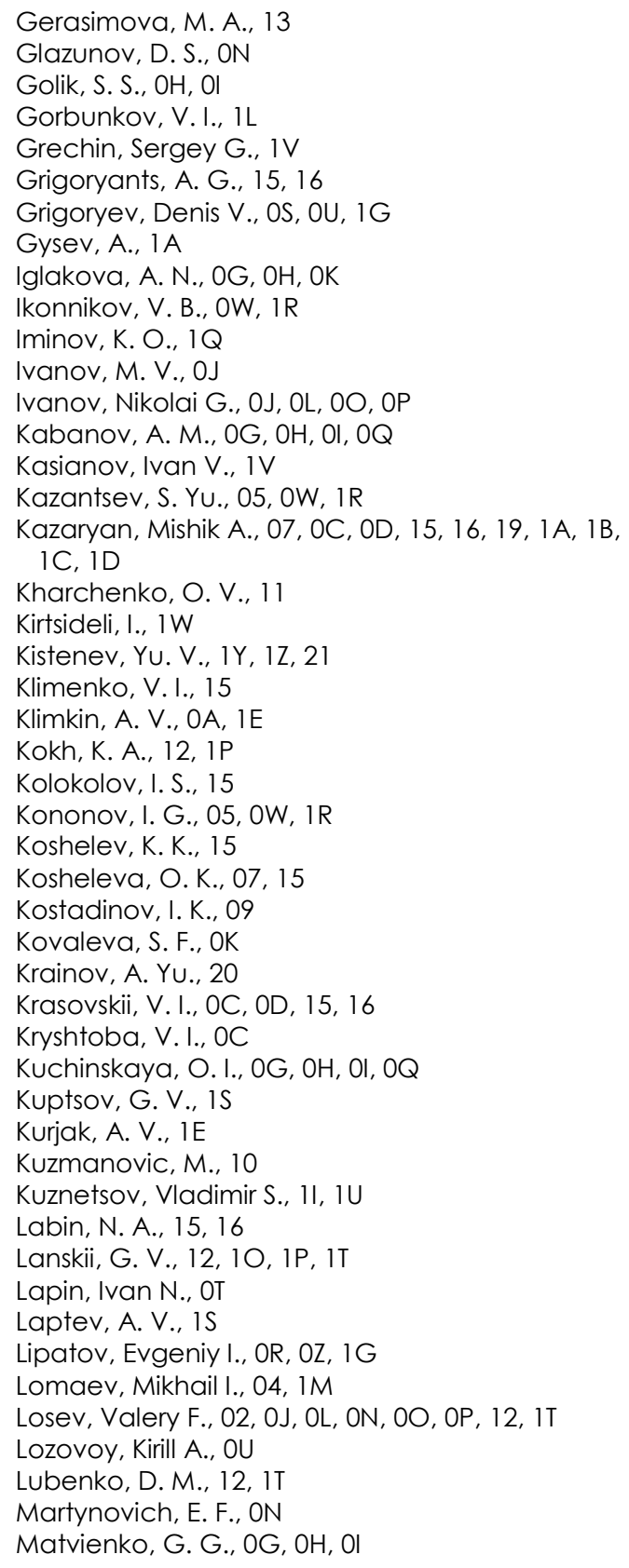


Mayor, A. Yu., Ol

Medvedenko, I. A., OK

Melchenko, S. V., 03

Minina, O. V., OQ

Mironov, S. YU., OP

Moiseeva, K. M., 20

Molloy, John F., $1 \mathrm{H}$

Momcilovic, M., 10

Morozova, E. A., 1B

Muravyev, E. N., 1B

Musayev, A., 18

Naftaly, Mira, $1 \mathrm{H}$

Nechaev, L. V., OE

Nesmelov, Sergey N., OU

Nikiforova, Olga Yu., 1X, IY

Nikolaev, V. V., $1 Y$

Novikov, Vadim A., OS

Orlovskii, Victor M., 14

Oshlakov, V. K., OG, OH

Oskomov, Konstantin V., OX, OY

Panarin, Victor A., 14, 11, $1 \mathrm{U}$

Panchenko, Alexei N., 04

Panchenko, Nikolai A., 04

Panchenko, Yurii N., 02, 08, 00

Paramonov, V.S., 15

Paramonova, G. M., 15

Parfenov, V., IW

Pashayev, A., 17, 18

Pechenitsin, Dmitrii S., 11

Pestryakov, E. V., IS

Petrov, A. $\vee ., O G, O H, O l, O Q$

Petrov, V. A., is

Petrov, V. V, 1 S

Plyaka, P. S., 15, 16

Podlesnykh, S. V., 05

Polunin, Yu. P., 09

Prokopiev, V. E., OA, OL, $1 \mathrm{E}$

Puchikin, A. V., 02

Rasmagin, S. I., OC

Reimer, I. V., 09

Rodin, S. A., OW, 1R

Romanovskii, O. A., 11

Sabotinov, N. V., 09

Sachkov, Victor I., 15, 16, 19, 1A

Sadikhov, I., 18

Sadovnikov, S. A., 11

Saifitdinova, A., IW

Salayev, E., 17

Savin, D. V., OW, 1R

Savovic, J., 10

Serykch, A. P., 21

Shakhsinov, G. Sh., 1Q

Shamanin, Igor V., 19

Shapovalov, A. V., 1Y, 1Z, 20

Shiganov, I. N., 15, 16

Shiyanov, D. V., 06

Shulepov, Mikhail A., OS, OU, OV, OX, OY, 14

Shumeiko, A. S., 09

Shumskii, V. K., 11
Skakun, Victor S., 11

Slabko, V. V., 13

Slyusareva, E. A., 13

Sokolova, E. B., $\mathrm{OH}, \mathrm{Ol}$

Sokolova, I. V., OF

Sokovikov, V. G., OA, 1 E

Soldatov, A. N., 09

Solomonov, V.I., $1 \mathrm{~L}$

Sorokin, Dmitry A., 1M

Sosnin, Edward A., 0Z, 11, 1K, $1 \mathrm{U}$

Stoiljkovic, M., 10

Suslov, Alexei I., 04

Svetlichnyi, Valery A., OB, OT, 12, 10, 1P

Tagiyev, B., 17, 18

Tarasenko, Viktor F., 04, OR, OS, OU, OV, OX, OY, 1G,

$11,1 \mathrm{M}$

Tchaikovskaya, O. N., OE, OF

Timofeeva, N. A., OW, 1R

Trtica, M. S., 10

Trunov, V.I., OM

Tunaboylu, B., 17

Vasil'eva, N. Y., OF

Vasilieva, A. V., 09

Victorova, Irina $\mathrm{A}$., $1 \mathrm{~K}$

Vinogradov, K. YU., 15

Vlasov, D. V., OC, OD

Vlasova, T. V., OC, OD

Voitsekhovskii, Alexandr V., OU

Volotko, Ivan I., IK

Vorobieva, L. P., IE

Vrazhnov, D. A., 1Y

Vusovich, O. V., OF

Yakovlev, S. V., 11

Yampolskaya, Sofiya A., 08

Yarzhemsky, V. G., 07

Yastremskii, Arkadii G., 08, 00

Zakharyan, R. A., 15, 1 A

Zandan, B., ON

Zemlyanov, A. A., OG, OH, Ol, OQ

Zivkovic, S., 10

Zvereva, G., 1N, IW 


\title{
Conference Committee
}

\author{
Conference Chairs
}

Victor F. Tarasenko, Institute of High Current Electronics SB RAS

(Russian Federation)

Gennadiy S. Evtushenko, National Research Tomsk Polytechnic

University (Russian Federation)

\section{Conference Organizing Committee}

Andrey M. Kabanov, V.E. Zuev Institute of Atmospheric

Optics SB RAS (Russian Federation)

Gennadiy S. Evtushenko, National Research Tomsk

Polytechnic University (Russian Federation)

Eduard A. Sosnin, Institute of High Current Electronics SB RAS

(Russian Federation)

Anton V. Klimkin, Scientific Secretary, V.E. Zuev Institute of

Atmospheric Optics SB RAS (Russian Federation)

Dmitriy Genin, Institute of High Current Electronics

SB RAS (Russian Federation)

Anna V. Vasilieva, National Research Tomsk State University SB RAS

(Russian Federation)

Mikhail V. Erofeev, Institute of High Current Electronics SB RAS

(Russian Federation)

Anatoly I. Fedorov, V.E. Zuev Institute of Atmospheric Optics SB RAS

(Russian Federation)

Ruslan M. Gadirov, Siberian Physical Technical Institute

(Russian Federation)

Marina A. Gerasimova, Siberian Federal University

(Russian Federation)

Fedor A. Gubarev, V.E. Zuev Institute of Atmospheric Optics SB RAS

(Russian Federation) and National Research Tomsk Polytechnical

University (Russian Federation)

Igor G. Ivanov, Southern Federal University (Russian Federation)

Ekaterina Yu. Kiselyova, National Research Tomsk Polytechnical University (Russian Federation)

Elena K. Klimkina, Center of Scientific and Technical Information

(Russian Federation)

Grigoriy V. Lanskiy, Institute of Monitoring of Climatic and Ecological Systems SB RAS (Russian Federation)

Mikhail Levitskiy, TOPAZ Research and Inculcation Enterprise

(Russian Federation) 
Anatoly N. Soldatov, National Research Tomsk State University (Russian Federation)

Valeriy A. Svetlichnyi, Siberian Physical Technical Institute (Russian Federation)

Victor F. Tarasenko, Institute of High Current Electronics SB RAS (Russian Federation)

Olga N. Tchaikovskaya, National Research Tomsk State University (Russian Federation)

Nikolay A. Yudin, National Research Tomsk State University (Russian Federation)

Alexander A. Zemlyanov, V.E. Zuev Institute of Atmospheric Optics SB RAS (Russian Federation)

\section{Conference Program Committee}

Victor F. Tarasenko, Institute of High Current Electronics SB RAS (Russian Federation)

Gennadiy S. Evtushenko, National Research Tomsk Polytechnic University (Russian Federation)

Georgii V. Mayer, National Research Tomsk State University (Russian Federation)

Anatoly N. Soldatov, National Research Tomsk State University (Russian Federation)

Alexander A. Zemlyanov, V.E. Zuev Institute of Atmospheric Optics SB RAS (Russian Federation)

Anton V. Klimkin, V.E. Zuev Institute of Atmospheric Optics SB RAS (Russian Federation)

Mikhail V. Erofeev, Institute of High Current Electronics SB RAS (Russian Federation)

Yurii S. Akishev, Troitsk Institute for Innovation and Fusion Research (Russian Federation)

Yury M. Andreev, Institute for Monitoring of Climatic and Ecological Systems SB RAS (Russian Federation)

Slavomir. S. Anufrick, Grodno State University (Belarus)

Peter A. Bokhan, Institute of Semiconductor Physics SB RAS

(Russian Federation)

Alexandr M. Boychenko, General Physics Institute (Russian Federation)

J. Gary Eden, University of Illinois at Urbana-Champaign (United States)

Konstantin N. Firsov, General Physics Institute (Russian Federation) Andrey A. Ionin, P.N. Lebedev Physical Institute (Russian Federation)

Mishik A. Kazaryan, P.N. Lebedev Physical Institute (Russian Federation)

Tatyana N. Kopylova, Siberian Physical Technical Institute (Russian Federation)

Bernard Lacour, Université Paris-Sud 11 (France) 
Eugene L. Latush, Southern Federal University (Russian Federation) Valery F. Losev, Institute of High Current Electronics SB RAS

(Russian Federation)

Vladimir V. Osipov, Institute of Electrophysics (Russian Federation)

Aleksey A. Pikulev, Russian Federal Nuclear Center - All-Russian

Research Institute of Experimental Physics (Russian Federation)

Hubert Piquet, Université de Toulouse (France)

Nikola V. Sabotinov, Institute of Solid State Physics (Bulgaria)

Ivan P. Spassovsky, Frascati Research Center ENEA (Italy)

Alexey B. Treshchalov, University of Tartu (Estonia)

Milan S. Trtica, Vinca Institute of Nuclear Sciences (Serbia)

Andreas Ulrich, Technische Universität München (Germany)

Georges Zissis, Université de Toulouse (France)

\section{Session Chairs}

A Gas and Plasma Lasers, Metal Vapor

Anatoly N. Soldatov, National Research Tomsk State University (Russian Federation)

Igor G. Ivanov, Southern Federal University (Russian Federation)

B Photonics of Optical Materials, Optoelectronics

Tatyana N. Kopylova, Siberian Physical Technical Institute (Russian Federation)

Olga N. Tchaikovskaya, National Research Tomsk State University (Russian Federation)

C Femtosecond Lasers and Laser Systems

Alexander A. Zemlyanov, V.E. Zuev Institute of Atmospheric Optics SB RAS (Russian Federation)

Valery F. Losev, Institute of High Current Electronics SB RAS

(Russian Federation)

D Laser Systems and New Laser and Optical Technologies, Laser Applications

Gennadiy S. Evtushenko, National Research Tomsk Polytechnic University (Russian Federation)

Mikhail Levitskiy, TOPAZ Research and Inculcation Enterprise (Russian Federation)

E Non-coherent UV and VUV-radiation Sources

Eduard A. Sosnin, Institute of High Current Electronics SB RAS

(Russian Federation)

Mikhail I. Lomaev, Institute of High Current Electronics SB RAS

(Russian Federation) 
F Conversion of Laser Radiation, Optoelectronic Devices

Yury M. Andreev, Institute for Monitoring of Climatic and Ecological Systems SB RAS (Russian Federation)

Valeriy A. Svetlichnyi, Siberian Physical Technical Institute (Russian Federation)

\section{$G$ Biophotonics}

Yury V. Kistenev, National Research Tomsk State University (Russian Federation)

Andrey M. Kabanov, V.E. Zuev Institute of Atmospheric Optics SB RAS (Russian Federation) 


\section{Introduction}

The International Conference: Atomic and Molecular Pulsed Lasers (AMPL) is devoted to the physical processes in laser active media, new active media and pumping methods; new lasers development technologies; fundamental issues of laser physics; and non-coherent UV and VUV-radiation sources. One of the principal goals of the conference is the contiguity of fundamental and applied sciences. Therefore, much attention was paid to the application of lasers and excilamps in science, engineering, medicine and other areas of activity as well as the discussion of problems with laser and excilamp-based apparatus and to new optical technologies.

This year's conference was organized by:

- V.E. Zuev Institute of Atmospheric Optics SB RAS (Russian Federation)

- Institute of High Current Electronics SB RAS (Russian Federation)

- Institute of Monitoring of Climatic and Ecological System SB RAS (Russian Federation)

- National Research Tomsk State University (Russian Federation)

- National Research Tomsk Polytechnic University (Russian Federation)

- V.D. Kuznetsov Siberian Physical Technical Institute (Russian Federation)

- P.N. Lebedev Physical Institute SB RAS (Russian Federation)

- A.M. Prokhorov General Physics Institute (Russian Federation)

The scientific program for this year's conference included the following sessions:

- Gas and Plasma Lasers, Metal Vapor

- Photonics of Optical Materials, Optoelectronics

- Femtosecond Lasers and Laser Systems

- Laser Systems and New Laser and Optical Technologies, Laser Applications

- Non-coherent UV and VUV-radiation Sources

- Conversion of Laser Radiation, Optoelectronic Devices

- Biophotonics

We wish to thank our sponsors for their contribution to the conference's success:

- Russian Foundation for Basic Research (Russian Federation)

- Siberian Branch of Russian Academy of Sciences (Russian Federation)

- TOPAZ Research and Inculcation Enterprise (Russian Federation)

- Crystaltechno Ltd. (Russian Federation)

- SP Equipment (Russian Federation) 
- Intech Analytics Corporation (Russian Federation)

- IC Specpostavka (Russian Federation)

- ClZ Ltd. (Russian Federation)

AMPL was first held in Tomsk in 1992, and in 1995 it became a biennial scientific forum hosted in Tomsk. The AMPL agenda covers the following issues:

- Physical processes in gas lasers including: excimer lasers, metal vapor lasers, and plasma lasers

- Dye lasers and photo-processes in complex organic molecules, photonics of optical materials

- Incoherent UV and VUV sources

- Diffuse discharges initiated by runaway electrons

- Conversion of laser radiation

- Optoelectronic devices

- Laser systems and advanced laser optics technologies

- Applications of lasers in different fields of science and technology, including ecology, medicine, industry, scientific research, struggle against terrorism

- The creation of laser-based devices

Also included in the AMPL program were related issues such as research in nonlaser pulsed UV sources, nonconventional isotope separation methods, optoacoustic devices, etc.; problems of femtosecond laser systems (since 2009), and a round-table discussion on bio-photonics (since 2015).

The conference also provides for special sessions. In particular, a special session devoted to diffuse discharges initiated by runaway electrons was organized two times $(2011$, 2013). Generally, about 200 reports are presented at the conference. The AMPL conference has gained wide acceptance in the scientific community involved with laser research, attracting scientists from different countries and cities within the Russian Federation, and this would be impossible without close cooperation with the Tomsk scientific and educational institutions.

Each conference is attended by students from National Research Tomsk State University and Tomsk Polytechnic University. As part of AMPL, an AMPL-SCHOOL conference of young scientists is held. During the conference, excursions are made to the scientific laboratories of institutes and universities in Tomsk.

This is the twelfth year of the conference, all of which have been chaired by Prof. V. F. Tarasenko from the Institute of High Current Electronics. The conference materials are published and can be found in issues of Atmospheric and Ocean Optics (Optika Atmospfery i Okeana), the Proceedings of SPIE (Proc. SPIE. Vol. 2619 
[1995]; Vol. 3403 [1997]; Vol. 4071 [1999]; Vol. 4747 [2001]; Vol. 5483 [2003]; Vol. 6263 [2005]; Vol. 6938 [2008]), Quantum Electronics (Kvantovaya Elektronika), and the Bulletin of the Tomsk Polytechnic University (Izvestia TPU).

The next AMPL conference in Tomsk will take place in September 2017.

Victor F. Tarasenko Andrey M. Kabanov 
Proc. of SPIE Vol. $9810981001-18$

Downloaded From: https://www.spiedigitallibrary.org/conference-proceedings-of-spie on 25 Apr 2023 Terms of Use: https://www.spiedigitallibrary.org/terms-of-use 